\title{
RESEARCH
}

\section{LDLR-mediated lipidome-transcriptome reprogramming in cisplatin insensitivity}

\author{
Wei-Chun Chang1,2, Hsiao-Ching Wang1, Wei-Chung Cheng1,2, Juan-Cheng Yang1,3, Wei-Min Chung1,2, Yen-Pin Ho1,2, \\ Lumin Chen ${ }^{4}$, Yao-Ching Hung ${ }^{1,2}$ and Wen-Lung Ma1,2,5
}

'Department of OBS \& GYN, Sex Hormone Research Center, Research Center for Tumor Medicine, and Chinese Medicine Research and Development Center, China Medical University Hospital, Taichung, Taiwan

2Department of Medicine, Graduate Institute of Biomedical Sciences, and Graduate Institution of Cancer Biology, School of Medicine, China Medical University, Taichung, Taiwan

${ }_{3}^{3}$ Research Center for Natural Products \& Drug Development, Kaohsiung Medical University, Kaohsiung, Taiwan

${ }^{4}$ Department of OBS \& GYN, BenQ Medical Center, Suzhou, Jiangsu Province, China

${ }^{5}$ Department of Nursing, Asia University, Taichung, Taiwan

Correspondence should be addressed to W-L Ma: maverick@mail.cmu.edu.tw

\begin{abstract}
Platinum-based therapy remains the cornerstone for cancer therapy; however, its efficacy varies. The role of lipoprotein receptor-mediated lipid entry for cancer development has been reported. Yet, the roles and mechanism of the low-density lipoprotein receptor (LDLR) in chemo-sensitivities are unknown. In the current report, we used epithelial ovarian cancer (EOC), composed of various cellularities, to study this issue. Using public cDNA microarray database and single cohort study, LDLR expressions were positively associated with epithelial ovarian carcinomas (EOCs) platinum-based chemotherapy patients' disease prognosis. In vitro and in vivo add-in/silencing LDLR was introduced to determine cisplatin sensitivity and cancer growth. Results revealed that knockeddown LDLR could sensitize while overexpressed LDLR could insensitize EOC cells to the cytotoxic effects of cisplatin. Moreover, the trans-omics approaches depicted an LDLR $\rightarrow$ LPC (Lyso-phosphatidylcholine) $\rightarrow$ FAM83B (phospholipase-related) $\rightarrow$ FGFRs (cisplatin sensitivity and phospholipase-related) regulatory axis. Finally, the manipulation of LDLR expression in EOC cells was found to determine the efficacy of cisplatin therapy in terms of tumor suppression. In conclusion, the LDLR $\rightarrow$ LPC $\rightarrow$ FAM83B $\rightarrow$ FGFRs axis is an example of tumor macroenvironmental regulation of therapy outcomes. Relatedly, LDLR expression could serve as a biomarker of chemotherapy sensitivity in EOCs. Significance: this study describes the role of LDLR in the development of insensitivity to platinum-based chemotherapy in epithelial ovarian cancer. The lipidome (e.g., LPC) and transcriptome (e.g., FAM38B) interactions revealed using trans-omics approaches an $\mathrm{LDLR} \rightarrow \mathrm{LPC} \rightarrow$ FAM83B $\rightarrow$ FGFRs regulatory axis in cancer cells, in an animal model, and in patients.
\end{abstract}

\author{
Key Words \\ - LDLR \\ - lysophosphotidylcholine \\ - EOC \\ - trans-omics \\ - bioinformatics
}

C) 2020 Society for Endocrinology Published by Bioscientifica Ltd. Printed in Great Britain
Endocrine-Related Cancer (2020) 27, 81-95 


\section{Introduction}

Platinum-based adjuvant chemotherapy is widely used in the management of patients with solid tumors, including gynecological malignancies (Lawrie et al. 2015, Falcetta et al. 2016), gut cancers (Malka et al. 2014, Galdy et al. 2016, Ishikawa et al. 2016), urinary tract carcinomas (Roupret et al. 2016), non-small-cell lung cancers (de Castria et al. 2013, Berghmans et al. 2017), and many other malignancies. Platinum can form DNA adducts in fast-growing cancer cells, a capacity which makes it an excellent tumor growth-suppressing agent. However, while platinum-based chemotherapies are commonly used to treat human malignancies, variations in the responsiveness and resistance of patients to such therapies are also seen (Johnson et al. 2011, Bellmunt et al. 2013, Poonawalla et al. 2015). The mechanisms underlying platinum-based chemotherapy sensitivity and resistance are yet to be elucidated; however, there is an interesting correlation between histological cellularity and platinum therapy responsiveness (Glasspool \& McNeish 2013, Falcetta et al. 2016, Ferreira et al. 2016, Prendergast et al. 2017).

Among various solid tumors, epithelial ovarian carcinomas (EOCs) appear to arise from diverse origins of epithelium including ovarian epithelial cells, the fallopian tubes, and cells that have migrated from the endometrium or the intestines (Vargas 2014, Klotz \& Wimberger 2017). Despite inconclusive evidence regarding the origins of EOCs, however, investigating the chemotherapy sensitivity of EOC cells might clarify why variations in platinum responsiveness occur among EOCs (McCluggage 2011). The different subtypes of EOCs can be classified histologically as serous, mucinous, endometrioid, and clear-cell EOCs (Vargas 2014), and previous studies have found that these subtypes of EOCs are associated with varying levels of platinum-based therapy efficacy (Glasspool \& McNeish 2013, Ledermann et al. 2014, Lawrie et al. 2015, Matulonis et al. 2016, DahmKahler et al. 2017). Serous EOC cells/patients have good sensitivity to chemotherapy (McCluggage 2011). In contrast, advanced clear-cell EOCs have been found to exhibit poor responses to platinum-based chemotherapy, with recurrent clear-cell carcinomas appearing to be particularly resistant to chemotherapy and difficult to treat (Sugiyama et al. 2000, Mizuno et al. 2006, Lee et al. 2011). Malignant mucinous tumors are epithelial ovarian tumors formed by cells that resemble the endocervical epithelium or intestinal epithelium (intestinal type), and the efficacy of platinum-based therapies against these tumors has also been found to be inferior (Ricci et al. 2018). Meanwhile, the clinicopathological features of malignant endometrioid EOCs are similar to those of clear-cell EOCs, as these subtypes are postulated to arise from the same cell type (Shevchuk et al. 1981) and to be platinum-based chemotherapy insensitive (Sugiyama et al. 2000).

Lipids are essential for biomass and building block synthesis, and lipids can also act as bioactive molecules, for example, as constituents of cellular membranes, or as an energy supply sufficient for the fast-growing nature of cancer cells (Ward \& Thompson 2012). Microscopically, endometrioid EOC exhibits an appearance similar to that of tubular glands and bears a resemblance to endometrium. Squamous differentiation is commonly seen in endometrioid EOC patients (Wagner et al. 1994), along with surrounding lipid droplet (LD)-vacuolated stromal tissue (Ulbright \& Roth 1985). In addition, clearcell EOC is also characterized by a significant amount of LD vacuoles in the cytoplasm (Nishimura et al. 2010). Moreover, the lipophilic nature of metastatic EOC cells appears to make them keen to migrate to the omentum (Nieman et al. 2011). All of those characteristics have raised the question of whether non-autonomous lipid providers, i.e. tumor macroenvironmental regulators (Lee et al. 2016) produced via the lipoprotein-mediated lipid route (lipoprotein/receptor-route) (Chang et al. 2017), might play roles in the development and disease progression of EOCs.

In the current study, we discovered that different levels of low-density lipoprotein receptor (LDLR; the gateway for non-autonomous lipid entry) expression in EOCs determine the platinum sensitivity of EOCs in an LDLR-dependent manner. In addition, LDLR alters the lipid and gene expressions of EOC platinum therapy sensitivity.

\section{Materials and methods}

\section{Patient cohort}

The paraformaldehyde-embedded EOC tissue samples analyzed in this study were obtained from patients diagnosed with EOC from 2008 to 2013 at China Medical University (Taichung, Taiwan). The patients were identified from a single cohort registered in the Cancer Registry Database of the hospital, and the gynecological pathology of each patient was classified according to the World Health Organization pathology classification. Access to the tissue samples was approved by the Internal 
Review Board of China Medical University Hospital (\#DMR101-IRB2-276 and CMU105-REC3-122(CR1)). Consent was obtained from each patient or subject after a full explanation of the purpose and nature of all the procedures used. The EOC subtypes were selected through a patient chart review and then confirmed based on the analysis of hematoxylin and eosin (H\&E)-stained and sectioned paraffin slides by two pathologists to exclude ambiguity or mixed histology between subtypes.

\section{Immunohistochemistry and quantitation of staining score}

In general, the histological studies were performed as described in previous studies (Hung et al. 2014, Chen et al. 2018) with some modifications. For general histologic inspection, we treated the tissue sections $(2 \mu \mathrm{M})$ with $H \& E$ or stained the sections with antibodies specific for LDLR and lipoprotein lipase (LPL) with an ABC kit (Vector Laboratories) to enhance the staining signals. Staining intensity was scored according to the Allred scoring system (Nose et al. 2009, Hammond et al. 2010) and our previous work (Lai et al. 2016). The proportion of cells that stained positive for LDLR and LPL was graded using a five-point scale according to the proportion of positive cancer cells $(1:<1 / 100 ; 2: 1 / 100$ to $1 / 10 ; 3: 1 / 10$ to $1 / 3 ; 4$ : $1 / 3$ to $2 / 3$; and $5:>2 / 3$ ). The intensity of staining was also graded on a five-point scale as follows: 1: none; 2 : weak; 3: intermediate; 4: mid-strong; 5 : strong. The proportions and intensity scores were next summed, averaged, and then compared with the associated histological reports. The slides were independently examined by three coauthors (WC Chang, MD; HS Wang; and YP Ho) who were blinded to the clinicopathological data. When there was a discrepancy (i.e., a score difference >3) between the scores given by the slide reviewers, the pathologists reassessed the slides using a double-headed microscope, and a consensus was reached. Finally, associations between the scores and the clinical data were investigated by another coauthor (YC Hung, MD).

\section{Reagents, cell culture, and lentiviral-based gene delivery}

Cells were maintained in various culture media (depending on the culture requirements) with 10\% FCS (Invitrogen), $1 \%$ L-glutamine, and $1 \%$ penicillin/streptomycin as described previously (Chang et al. 2017). The HEK293T (ATCC; HTB52) and EOC (MDAH-2774; SKOV3, HTB-77; OVCAR3, HTB-161; ES2, CRL-1978; TOV-112D,
CRL-11731; TPOV-21G, CRL-11730) cell lines were purchased from ATCC.

The following antibodies were used: LDLR (for IHC: GeneTex, GTX61553; for immunoblot: Santa Cruz, sc-373830), LPL (Santa Cruz, sc-32885), VEGFR (Santa Cruz, sc-6251), phospho-FAK (Cell Signaling Technology, \#3283; Try397), FAK (Cell Signaling Technology, \#3285), MEK1/2 (Cell Signaling Technology, \#8727), actin (Santa Cruz, sc-47778), and tubulin (Abcam, ab-6046). The following chemicals were also used: cisplatin (Sigma-Aldrich, P4394), DOTAP (1,2-dioleoyl3-trimethylammonium-propane; Avanti, 890890P), and lyso-phosphatidylcholine (Avanti, 855675P).

\section{Lentiviral-based gene delivery}

LDLR knockdown or overexpression clones were engineered by the stable transfection of human LDLR cDNA (pLenti-C-mGFP-LDLR, RC200006L2; OriGENE, Rockville, MD, USA) or pLKO.1-shLDLR (targeting sequence shown in Supplementary Table 1, see section on supplementary materials given at the end of this article) and then selected after exposure to puromycin $(10 \mu \mathrm{M})$ for a period of time (Ma et al. 2012, 2014). The pLKO-shLuciferase, shLDLR, shFAM83B (Supplementary Table 2) plasmids were obtained from the National RNAi Core Facility Platform (Institute of Molecular Biology/ Genome Research Center, Academia Sinica, supported by the National Core Facility Program for Biotechnology; grant NSC107-2319-B-001-002). The pBabe and pWPI (Addgene) vector-based LDLR cDNA expression plasmids were constructed as previously reported (Ma et al. 2008). The lentiviral production and infection procedures used in this study followed those reported previously (Ma et al. 2012). In brief, psPAX2 (packaging plasmid) and pMD2G (envelope plasmid) (Addgene) were co-transfected into HEK293T cells. We then harvested virus-containing media to infect the EOC cells. The GFP+ cell populations, as determined by flow cytometry analysis (BD LSR II Flow Cytometry), were used to test the infection efficiencies.

\section{Colony formation, cytotoxic measurement, and IC 50 values}

Colony-forming assays were performed as previously reported (Chen et al. 2014). Briefly, $1 \times 10^{4}$ cells/dish were seeded onto $3.5-\mathrm{cm}$ plates with DMEM in 10\% FBS with various treatments for 7 days. After the treatments, $1 / 3$ of the total volume of the $10 \%$ formaldehyde solution was added to fix the cells, which were then allowed to stain (c) 2020 Society for Endocrinology Published by Bioscientifica Ltd. Printed in Great Britain 
with crystal violet for $5 \mathrm{~min}$. After being washed with PBA, the colonies were photographed.

For the cell viability assay, cells were seeded in 96-well plates $\left(5 \times 10^{3}\right.$ cells/well) and incubated overnight for attachment, and were then treated with the indicated doses of drugs in normal media for $48 \mathrm{~h}$. After the treatments, the media were replaced with WST- $1(0.5 \mathrm{mg} / \mathrm{mL})$ at $37^{\circ} \mathrm{C}$ for at least $1 \mathrm{~h}$. After the removal of excess WST- 1 (Sigma-Aldrich), the colorimetric absorbance of the cells at $490 \mathrm{~nm}$ was read. The readings of the measured values of 50\% inhibition concentration (IC50) (Chou 2010) for each drug were determined by CalcuSyn software (Chou $\&$ Talalay 1984) (BioSoft).

\section{Experimental animal and xenograft implantation tumor model}

Athymic nude female mice aged 6-8 weeks old (Foxn $1{ }^{n u}$ ) were purchased from the National Laboratory Animal Center (NLAC), Taiwan. Subcutaneous implantation of $1 \times 10^{6}$ cells/100 $\mu \mathrm{L}$ PBS and matrigel (1:1) in both flanks was performed on each mouse. The mice were then randomly divided into experimental groups as the tumors grew to $500-\mathrm{mm}^{3}$, and the size of each tumor was measured twice/week. The mice were treated with/without cisplatin ( $6 \mathrm{mg} / \mathrm{kg} / \mathrm{mice}$ or equal volume of phosphate buffered saline; I.P., every other day for 4 weeks). The mice were then killed and the tumors were harvested. All the animal studies were performed under the supervision, guidelines, and approval of the China Medical University Animal Care and Use Committee (\#CMOIACUC-2018-089).

\section{Real-time RT-PCR and primers}

The protocol for detecting mRNA expression followed that detailed in a previous publication (Chiang et al. 2017) with some modifications. Total RNA was isolated from the tissue using the Trizol $^{\mathrm{TM}}$ reagent (Invitrogen) according to the manufacturer's protocol. The mRNA levels of various genes were measured by qPCR using the Bio-Rad CFX 96 sequence detection instrument. The levels of mRNA were normalized with GAPDH mRNA. The SYBR probe (BioRad) was used as the fluorogenic probe to determine the threshold cycle (Ct), and the forward and reverse primers are shown in Supplementary Table 1.

\section{Lipid profiling for lipidome analysis}

After the cells $(1500$ cells $/ \mu \mathrm{L} \times 300 \mu \mathrm{L})$ were washed with $\mathrm{Ca}^{2+} / \mathrm{Mg}^{2+}$-free PBS, the lysates were then subjected to

(c) 2020 Society for Endocrinology Published by Bioscientifica Ltd. Printed in Great Britain lipid profiling executed by Lipotype GmbH (Dresden, Germany) (Ejsing et al. 2009, Sampaio et al. 2011, Levental et al. 2017). Lipidomes were prepared from at least three replicates of each sample for all the experiments using the following procedures.

\section{Nomenclature}

The following lipid names and abbreviations were used: Cer, ceramide; Chol, cholesterol; DAG, diacylglycerol; HexCer, glucosyl/galactosyl ceramide; PA, phosphatidic acid; PC, phosphatidylcholine; PE, phosphatidylethanolamine; PG, phosphatidylglycerol; PI, phosphatidylinositol; PS, phosphatidylserine; and their respective lysospecies lyso-PA (LPA), lyso-PC (LPC), lyso-PE (LPE), lyso-PI (LPI), and lyso-PS (LPS); and their ether derivatives PC O-, PE O-, LPC O-, and LPE O-; SE, sterol ester; SM, sphingomyelin; SLs, sphingolipids; and TAG, triacylglycerol. Lipid species were annotated according to their molecular composition as follows: (lipid class)-(sum of carbon atoms in the fatty acids):(sum of double bonds in the fatty acids);(sum of hydroxyl groups in the long-chain base and the fatty acid moiety) (for example, SM-32:2;1). Where available, individual fatty acid compositions following the same rules were given in brackets (for example, 18:1;0-24:2;0).

\section{Lipid extraction for MS lipidomics}

Lipids were extracted using a two-step chloroform/ methanol procedure. Samples were spiked with an internal lipid standard mixture containing cardiolipin (CL), 16:1/15:0/15:0/15:0; Cer, 18:1;2/17:0; DAG, 17:0/17:0; HexCer, 18:1;2/12:0; LPA, 17:0; LPC, 12:0; LPE, 17:1; LPG, 17:1; LPI, 17:1; LPS, 17:1; PA, 17:0/17:0; PC, 17:0/17:0; PE, 17:0/17:0; PG, 17:0/17:0; PI, 16:0/16:0; PS, 17:0/17:0; cholesterol ester (CE), 20:0; SM, 18:1;2/12:0;0; TAG, 17:0/17:0/17:0; and Chol. After extraction, the organic phase was transferred to an infusion plate and dried in a speed vacuum concentrator. Each first-step dry extract was resuspended in $7.5 \mathrm{mM}$ ammonium acetate in chloroform/methanol/propanol (1:2:4, v/v/v), and each second-step dry extract was resuspended in a 33\% ethanol solution of methylamine/chloroform/ methanol $(0.003: 5: 1, \mathrm{v} / \mathrm{v} / \mathrm{v})$. All liquid handling steps were performed using the Hamilton Robotics STARlet robotic platform with the Anti-Droplet Control feature for organic solvent pipetting.

\section{MS data acquisition}

Samples were analyzed by direct infusion on a Q-Exactive mass spectrometer (Thermo Scientific) equipped with 
a TriVersa NanoMate ion source (Advion Biosciences). Samples were analyzed in both the positive and negative ion modes with a resolution of 280,000 at $\mathrm{m} / \mathrm{z}=200$ for MS and 17,500 for MS/MS experiments in a single acquisition. MS/MS was triggered by an inclusion list encompassing corresponding MS mass ranges scanned in 1-Da increments. Both MS and MS/MS data were combined to monitor CE, DAG, and TAG ions as ammonium adducts; PC and PC O- as acetate adducts; and CL, PA, PE, PE O-, PG, PI, and PS as deprotonated anions. Only MS was used to monitor LPA, LPE, LPE O-, LPI, and LPS as deprotonated anions; Cer, HexCer, SM, LPC, and LPC $\mathrm{O}$ - as acetate adducts; and $\mathrm{Chol}$ as an ammonium adduct of an acetylated derivative (Surma et al. 2015).

\section{Data analysis and post-processing}

Lipid identification using LipotypeXplorer (2) was performed on unprocessed mass spectra. For the MS-only mode, lipid identification was based on the molecular masses of the intact molecules. The MS/MS mode included the collision-induced fragmentation of lipid molecules, and lipid identification was based on both the intact masses and the masses of the fragments. Prior to normalization and further statistical analysis, the lipid identifications were filtered according to mass accuracy, occupation threshold, noise, and background (Klose et al. 2013). Lists of identified lipids and their intensities were stored in a database optimized for the particular structure inherent to lipidomic datasets. The intensity of lipid class-specific internal standards was used for lipid quantification (Liebisch et al. 2006). The identified lipid molecules were quantified by normalization to a lipid class-specific internal standard. The amounts in p-moles of individual lipid molecules (species of subspecies) of a given lipid class were summed to yield the total amount of the lipid class. The amounts of the lipid classes may be normalized to the total lipid amount, yielding mol. \% per total lipids.

\section{Lipidomic data processing}

The lipid profiling data for each sample were scale normalized by the total amount of lipid. Those lipids with at least a two-fold change between the LDLR knockdown and control cells were identified as the lipids that were significantly regulated by LDLR. Then, Fisher's exact test was conducted to test the enrichment of the significantly regulated lipids in each lipid class (such as PC, PE, and LPC).
TCGA-database DriverDB.v2 and KMplotter meta-analysis for cancer survival analysis, and bioinformatics for trans-omics approach

\section{Cancer survival score}

The previously developed DriverDB (Cheng et al. 2014, Chung et al. 2015), a database that incorporates more than 9500 cancer-related RNA-seq datasets and more than 7000 exome-seq. datasets from The Cancer Genome Atlas (TCGA), was used in this study. In the DriverDB, there are 420 primary tumors and 37 adjacent normal tissues (including 34 normal-tumor pairs) in the EOC dataset from TCGA. For the survival analysis of TCGA data, Kaplan-Meier survival curves were drawn and the logrank test was performed to assess the differences between the patient groups stratified by the median of gene expression. A $P$ value of less than 0.05 was considered statistically significant.

With regard to the Web-based KMplotter platform used for the evaluation of the hazard ratio (HR) scores of the pathways (cluster of genes) with respect to patient survival, the following previously established formula was used (Chang et al. 2016, 2017):

HR score $=($ Avg. of HR of gene sets $)$

$$
=\frac{\Sigma(\mathrm{HR} n-1) \times\left(-\log _{10}(P \text {-value })\right)}{n} \times 100
$$

In order to evaluate the impact of each gene, the absolute value of the HR for that gene minus 1 was calculated. To adjust for the effects of the genes, the HR value for each gene was multiplied by negative $\log _{10}(P$ value $)$ to balance the importance of the genes. The summed score was then divided by the number of genes and multiplied by 100 to obtain the HR score, or the average HR of all the genes.

\section{Trans-omics approach}

The raw reads of RNA-seq data were aligned with TopHat 2.0.13 (Kim et al. 2013) to human genome (GRCh38) with default parameters and then were assembled by Cufflink 2.2.1 (Trapnell et al. 2012), using Ensembl v90 annotations. The abundance of gene expression was calculated by fragments per kb of exon per million fragments mapped (FPKM). The normalized expression of lipidome data was obtained from Lipotype Gmbh. The differentially expressed (DE) genes/lipid species between the knocdown and control cell lines were identified by the criterion: $\mid \log 2$ (Fold change) $\mid>1$. For the DE genes, we performed functional enrichment analysis, as described in our previous studies (Cheng et al. 2014, 
Chung et al. 2016), to interpret their biological functions. In brief, we used the topGO and GeneAnswers packages of Bioconductor to calculate the topology of the GO graph. We used collections from KEGG (Kanehisa et al. 2012), PID (Schaefer et al. 2009), Biocarta (http://www.biocarta. com/), REACTOME (Croft et al. 2011), and MSigDB (Subramanian et al. 2005) to annotate the DE genes in pathway level. For the DE lipid species, we performed Fisher's exact test to identify the significant lipid classes with enriched DE lipid species. Finally, we focus on the DE genes related to the significant lipid class according to the information GO, KEGG and REACTOME database.

\section{Preparation and characterization of LPC liposome}

The liposome was prepared by thin-layer hydration (Jang et al. 2013) followed by application of the membrane protrusion method (Ong et al. 2016) with some modifications. First, we hydrated a mixture of DOTAP $(\mathrm{mw}=698.5 \mathrm{~g})$ or LPC $(\mathrm{mw}=495.63 \mathrm{~g})$ : cholesterol $(\mathrm{mw}=386.6 \mathrm{~g})=1: 1$ (molar ratio) with purified water (Milli-Q Plus, Millipore). The mixture was then incubated at $65^{\circ} \mathrm{C}$ for an hour, and then sonicated in a $65^{\circ} \mathrm{C}$ waterbath for $30 \mathrm{~min}$. The mixture was then subjected to membrane protrusion (mini-Extruder, Avanti Polar Lipid, Ltd.) with a 200-nm pore size membrane (Avanti Polar Lipid, Ltd.), being extruded 20 times to form pre-liposome. The pre-liposome was then subjected to protrusion with a 100 -nm pore size membrane, being extruded another 15 times. The liposome size and size distribution were then determined by photon correlation spectroscopy (Zetasizer Nano-ZS90, Malvern Instruments Ltd., Malvern, Worcestershire, UK). The 10- $\mu \mathrm{L}$ liposomes were dispersed with $500 \mu \mathrm{L}$ purified water in a low volume disposable sizing cuvette. The particle size and size distribution were measured in terms of ZAve and polydispersity index (PDI), respectively.

\section{RNA sequencing for transcriptome analysis}

RNA-Seq libraries were prepared using the Agilent SureSelect RNA Library Kit and were sequenced using Illumina Hiseq4000 150-nt PairedEnd to produce the reads ( 25 million reads per sample). The reads were aligned with TopHat 2.0.13 to GRCh38 with default parameters and then were assembled by Cufflink 2.2.1 using Ensembl v79 annotations. Gene expression was measured in fragments per $\mathrm{kb}$ of exon per million fragments mapped (FPKM). For the differentially expressed genes regulated with LDLR, we performed functional enrichment analysis, as described in our previous studies (Cheng et al. 2014, Chung et al. 2015), to interpret their biological functions.

\section{Statistics}

The Student $t$-test or the chi-square analysis was used to identify significant differences between groups or categorical variables. A $P$ value less than 0.05 was considered significant. All data are reported as the mean \pm s.E.M.

\section{Results}

\section{LDLR expression is a major determinant of platinum chemosensitivity}

Given our hypothesis that the entry of tumor macroenvironmental lipid through the lipoprotein/ receptor-route might contribute to the development of EOC subtypes, we examined the expression of LDL/Rroute-related genes (Chang et al. 2017) in EOC patients. The LDL/R-route components include LDLR (the entrance gate for LDL) and LPL (lipoprotein lipase; which is responsible for unloading lipid from $\mathrm{LDL}$ ). As indicated by the results shown in Fig. 1A, B and C, LDLR and LPL were expressed throughout the various EOC subtypes. However, predominantly weak LDLR staining was seen in serous and mucinous EOC patients, whereas predominantly strong LDLR staining was seen in endometrioid and clear-cell EOC patients. Compared to that for LDLR, the expression pattern of LPL was more consistent across the various subtypes of EOC.

In order to validate the roles of LDLR in the responses of EOC cells to chemotherapy, we examined the LDLR expressions of EOC cells from serous (OVCAR3, SKOV3), endometrioid (MDAH-2774, TOV-112D), and clearcell (TOV-21G, ES2) EOCs (Fig. 1D). We found that the endometrioid and clear-cell EOCs had abundant LDLR. Meanwhile, serous EOC was the subtype most sensitive to cisplatin, with a low IC 50 value compared to those for the endometrioid and clear-cell EOCs (Fig. 1E). A similar phenomena was observed in the colony formation assay results (Fig. 1F).

In order to examine the impact of LDLR expressions on cisplatin responsiveness in vitro, shRNA targeting LDLR expression was introduced in endometrioid and clear-cell EOCs, while stably transfected LDLR cDNA was introduced in serous EOC (Fig. 2A). We found that the LDLR cDNA could reduce, while the shRNA could enhance cisplatin 

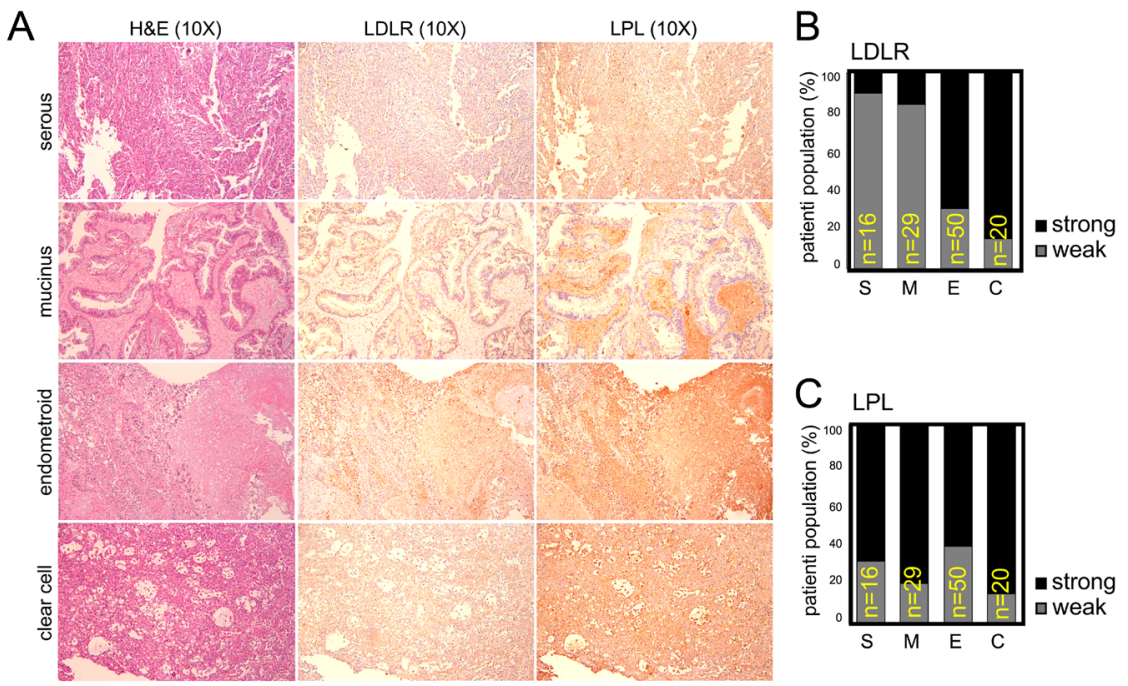

\section{Figure 1}

Differential expressions of LDLR in EOC subtypes. (A) Histological H\&E staining (left column) and immunohistochemistry (IHC) staining of LDLR

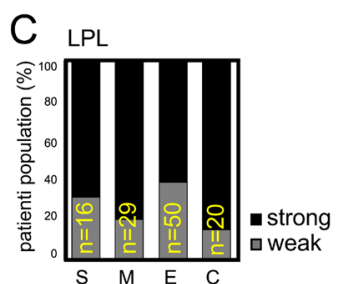
(middle column) and LPL (right column) of serous EOC (1st row), mucinous EOC (2nd row), endometrioid EOC (3rd row), and clear-cell EOC (4th row) cells. (B and C) Quantitation of IHC scores of LDLR (B) and LPL (C) in EOC subtypes. The patient numbers are serous $(S ; n=16)$, mucinous ( $\mathrm{M} ; n=29)$, endometrioid $(\mathrm{E} ; n=50)$, and clear-cell (C; $n=20)$. 'Strong' indicates an IHC score of 3 or above, while 'weak' indicates an IHC score lower than 3. (D) Differential LDLR (upper panel) and LPL (middle panel) expression in EOC cells. S: OVCAR3, SKOV3; E: MDAH-2774, TOV-112D; C: TOV-21G, ES2. Actin served as the loading control (lower panel). (E) Cisplatin cytotoxic IC 50 value of EOC cells. The unit of the IC 50 values is $\mu \mathrm{M}$. (F) Differential inhibitory efficacies of long-term (14

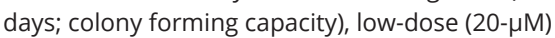
cisplatin treatments on SKOV3, TOV-112D, or ES2 cells. All in vitro data are from at least three representative experiments.

colony-suppressing capacity (Fig. 2B and C) and cytotoxic efficacy (Fig. 2D and E). Furthermore, the IC 50 value of cisplatin could be significantly altered in TOV-112D (from $427 \pm 27.4$ to $111 \pm 32.6 \mu \mathrm{M}$ ), TOV-21G (from $178 \pm 72.7$ to $99 \pm 33.7 \mu \mathrm{M}$ ), MDAH-2774 (from $125 \pm 26.6$ to $63 \pm 0.5 \mu \mathrm{M}$ ), and SKOV3 (from $8.9 \pm 1.06$ to $297.2 \pm 15.43 \mu \mathrm{M}$ ) cells.

In brief, the results shown in Figs 1 and 2 demonstrated that LDLR expression could potentially serve as a valuable biomarker for cisplatin regimens.

\section{Trans-Omics bioinformatics approach illustrated potential mechanism}

Considering the nature of LDLR for lipid importing, we performed lipidome analysis of three subtypes of EOC cells using shotgun lipid profiling technology. The lipid profiles were differentially expressed in six EOC cell lines, including with specific preferences (Fig. 3A). The etherlinked phospholipids were highly expressed in serous and endometrioid EOC cells. On the other hand, the storage lipids (DAG and TAG, which exist in endoplasmic reticulum and $\mathrm{LD}$ ) were predominantly expressed in endometrioid and clear-cell EOC cells.

In order to determine the molecular mechanism of LDLR-mediated cisplatin insensitivity, we subjected two types of EOC cells (MDAH-2774 and TOV-21G; control vs knockdown LDLR) to transcriptome with RNA nextgeneration sequencing technology (RNAseq) and lipidome with shotgun LC-MS/MS profiling. The transcriptome and lipidome were then subjected to Trans-Omics analyses. Using integrative platform of transcriptome and Lipidome (unpublished works), we were able to associated genes function with GO terms and KEGG lipid metabolism map to interpret the relationship of gene and lipid expression acquired in the experiments.

The lipidome analysis revealed that lysophosphatidylcholine (LPC; upregulated; red-color labeled) and ether-linked phosphatidyletholamine (PE O-; downregulated; black-bold labeled) were significantly altered by LDLR knockdown (Fig. 3C). Under the same experimental design, we found that 1404 genes were consistently altered (Fig. 3D). Through gene ontologybased annotation and functional enrichment analysis, we were then able to determine the top ten enriched pathways in terms of molecular function, which are listed in Fig. 3E. It was surprising to find that the lipid metabolism-related pathways were not prioritized in the LDLR-knockdown list, whereas transmembrane receptor activity and transcription factor-binding activity were.

The lysophatidyl lipids and phosphatidyl lipids, which are involved in the Lands cycle (converting by LPCAT1/2/3 and PLA2) (Moessinger et al. 2014), differ in
2020 Society for Endocrinology Published by Bioscientifica Ltd. Printed in Great Britain 
A
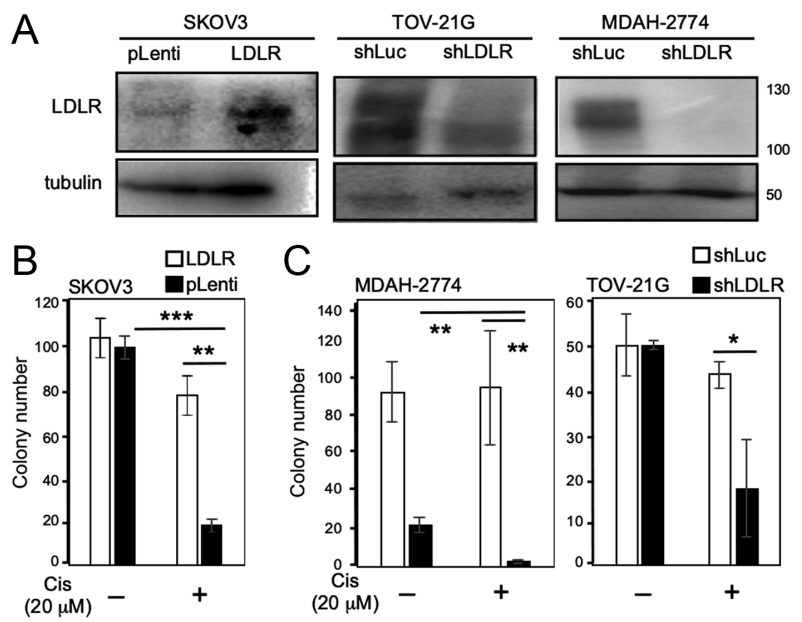

C
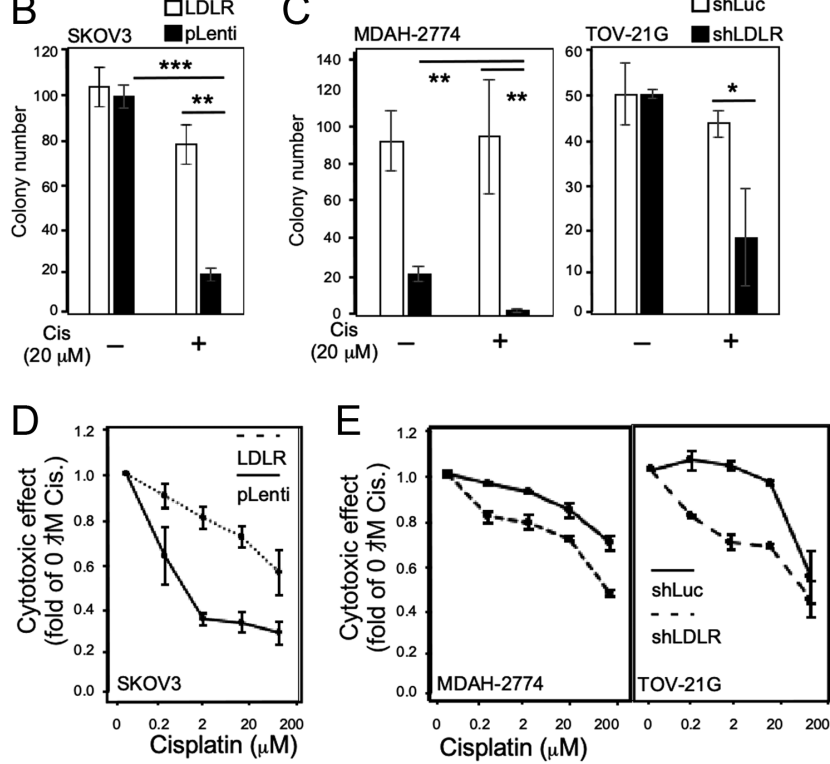

Figure 2

The expressions of LDLR determine cisplatin sensitivity in EOC cells. (A) Manipulation of LDLR expressions in EOC cells. Left-hand side panel: stable transfection of LDLR CDNA in SKOV3 cells. pLenti: control empty vector; LDLR: pLenti-LDLR cDNA. Middle panel: stable transfection of shRNA targeting LDLR in TOV-21G cells. shLuc: pLKO.1 vector constructed shRNA targeting luciferase gene; shLDLR: pLKO.1-shLDLR targeting LDLR expression. Right-hand side panel: stable transfection of shRNA targeting LDLR in MDAH-2774 cells. (B) Cell growth inhibitory efficacy of long-term, low-dose cisplatin treatments (Wang et al. 2018) on parental and stable LDLR expression SKOV3 cells. (C) Cell growth inhibitory efficacy of long-term, low-dose cisplatin treatments on shLuc and shLDLR knockdown TOV-21G (left-hand side panel) and MDAH-2774 (right-hand side panel) cells. (D) Cytotoxic effect of cisplatin on parental and stable LDLR expression SKOV3 cells. (E) Cytotoxic effect of cisplatin on shLuc and shLDLR knockdown TOV-21G (left-hand side panel) and MDAH-2774 (right-hand side panel) cells. The ** indicates a significant difference due to a $P$ value $<0.01$, and $* \star \star$ indicates a $P$ value $<0.001$

lyso-groups, so the trans-omics analysis strategies were designed as follows: 1st, transmembrane receptor activity genes were revealed by transcriptome analyses; 2 nd, lysophospholipid-related phospholipase genes were revealed in transcriptome analyses; 3rd, phospholipase expression was negatively correlated with LDLR expression (for knockdown experimental design); and 4th, phospholipase genes significantly correlated to cancer survival were revealed in TCGA (The Cancer Genome Atlas) database.

The analysis of the Fig. 3D results shown in Fig. 3F indicated that there were no genes identified via all four strategies. Interestingly, however, there was one gene identified via strategies 1,2 , and 3 (SNCB, synuclein $\mathrm{B}$; upregulated); one identified via strategies 1 and 3 (FAM83B, family with sequence similarity 83 member B; downregulated); and one identified via strategies 1 and 4 (VEGFR; downregulated). There were also two genes identified via strategies 1, 2, and 4 (FGFR1 and FGFR3; upregulated). Those analysis results suggested an indirect regulation of phospholipase (FAM83B or SNCB), LDLR, and RTK (VEGFR or FGFRs) expressions in EOC cells.

\section{LDLR $\rightarrow$ LPC $\rightarrow$ FAM83B $\rightarrow$ FGFR3 regulatory axis in platinum sensitivity}

In order to verify the correlations of regulation among gene expressions, we examined the LDLR-knockdown effect on SNCB, FAM83B, and RTKs. The results were consistent with the transcriptome (Fig. 3F) in that FGFR1 3 were downregulated (Fig. 4A). Meanwhile, knockdown LDLR also downregulated both protein (Fig. 4B, upper panel) and mRNA (Fig. 4B, lower panels) of FAM83B in EOC cells. In order to characterize the relationship of LDLR vs FAM83B vs FGFRs, we knocked down FAM83B in EOC cells. We found knockdown FAM83B did not alter LDLR, but downregulated FGFR1 3 in mRNA level (Fig. 4C). This indicating FAM83B is the downstream of LDLR, and upstream of FGFRs. As we verify the consequences of LDLR $\rightarrow$ FAM83B $\rightarrow$ FGFRs axis, we examined the FGFRrelated downstream signals. We found pFAK, total FAK, and total MEK abundance were significantly decreased (Fig. 4D). At last, we used TCGA database with DriverDB. v2 platform to analyze the association of FAM83B in EOC survival, and we found it to be a negative risk factor for patients (Fig. 4E).

We then tested whether the LDLR-mediated FAM83B $\rightarrow$ FGFRs regulatory axis affects platinum sensitivity in the context of an LPC-associated event. We compared the cytotoxic effects of direct treatment with cisplatin, treatment with liposomeencapsulated cisplatin (DOTOP-liposome; 1,2-dioleoyl3-trimethylammoniumpropane), and treatment with LPC-liposome-encapsulated cisplatin on the insensitive MDAH-2774 cells. Only $20 \mu \mathrm{M}$ of cisplatin encapsulated in LPC-liposome exhibited excellent cytotoxic efficacy (Fig. $5 \mathrm{~A}$; lane 1 vs 5 vs 6 ). Meanwhile, neither LPC-cisplatin co-treatment (non-liposome) (Fig. 5A; lane 6 vs 7) nor DOTAP-liposome-cisplatin (Fig. 5A; lane 3 vs 4 ) showed such efficacy. When the effect of FAM83B knockdown on cisplatin cytotoxicity was tested, it was found that two clones of FAM83B knockdown could significantly facilitate cisplatin cytotoxic activity in MDAH-2774 cells 
A

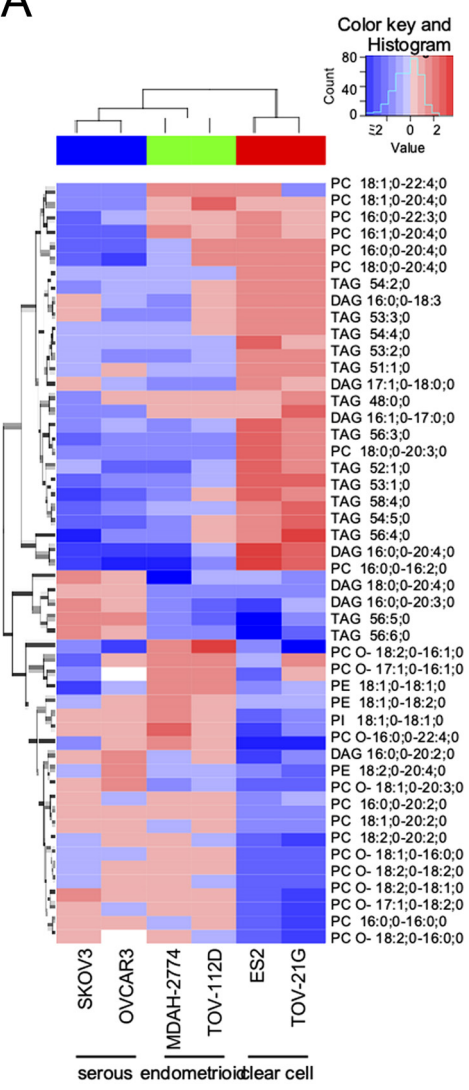

B Lipidome reprogramed by LDLR knockdown in EOC cells

\begin{tabular}{rcccc} 
class & $\begin{array}{c}\text { sign. } \\
\text { count }\end{array}$ & $\begin{array}{c}\text { total } \\
\text { count }\end{array}$ & pmol.log & p.value \\
\hline CE & 1 & 15 & 0.38 & 0.44 \\
Cer & 1 & 28 & 0.00 & 1 \\
DAG & 1 & 108 & 0.60 & 0.25 \\
HexCer & 1 & 13 & 0.40 & 0.40 \\
LPC & 2 & 7 & 1.40 & $* 0.04$ \\
LPE & 2 & 10 & 1.17 & 0.07 \\
PO & 2 & 182 & 0.96 & 0.11 \\
PC O- & 4 & 159 & 0.19 & 0.64 \\
PE & 8 & 154 & 0.43 & 0.37 \\
PE O- & 18 & 147 & 3.9 & $\star \star \star 1.25-E 04$ \\
SM & 1 & 20 & 0.27 & 0.53
\end{tabular}

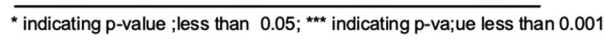

C

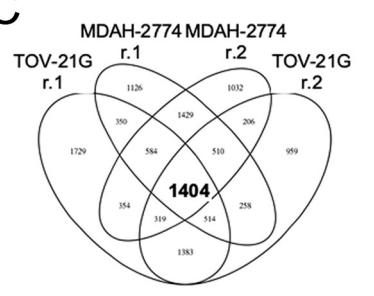

E
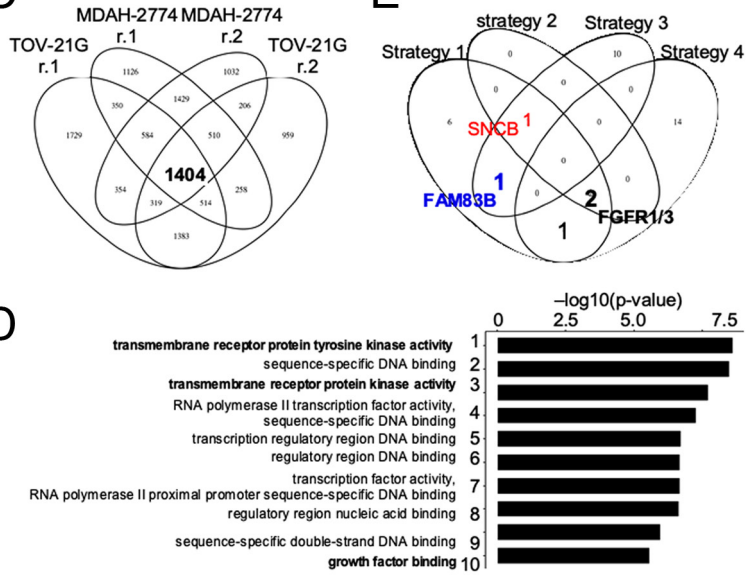

Figure 3

Transcriptome vs lipidome trans-omics approaches for potential molecular regulations. (A) Heat-map lipid profiling of six types of EOC cells, including serous (SKOV3, OVCAR3), endometrioid (MDAH-2774, TOV-112D), and clear-cell (ES2, TOV-21G) lines. The spectrum from blue to red indicates the variation of lipid species among the cells. (B) Lipidome analyses of lipid species comparing shLuc vs. shLDLR in MDAH-2774 and TOV-21G cells. The Y-axis shows the lipid species change $P$ value, where the threshold $>-\log _{10}(1.4)$ indicates significant alteration (red-colored). LPC was increased and PE O- was decreased when the LDLR was knocked down. (C) Replicated transcriptome analysis by RNAseq was performed to compare shLuc vs shLDLR in MDAH-2774 and TOV-21G cells. The overlapped transcriptome showed that 1404 genes were consistently altered. (D) Pathway enrichment analysis by GO-term followed with GSEA analysis. The top 10 enriched pathways were ranked from highest to lowest $P$ value(-log10). (E) Trans-omics analyses of transcriptome and lipidome profiles. The four selection criteria were implemented in the analyses. Strategy 1: transmembrane receptor activity genes were revealed by transcriptome analyses; Strategy 2: lyso-phospholipid-related phospholipase genes were revealed in transcriptome analyses; Strategy 3: phospholipase expression was negatively correlated with LDLR expression (for knockdown experimental design); Strategy 4: phospholipase genes

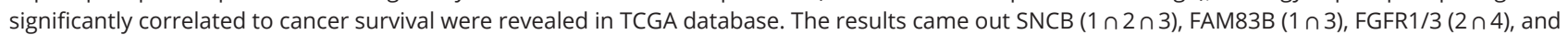
FGFR1 ( $1 \cap 4)$. The lipid profiling data were from two replicated experiments, and the gene expression and cytotoxic assay results were from at least three independent experiments.

(Fig. 5B). In testing the LPC-liposome effect on gene expressions, meanwhile, we found that both FAM83B (Fig. 5C) and FGFRs (Fig. 5D) were upregulated in comparison with DOTOP liposome. Except for the gene regulation in cultured EOC cells, we also examined LDLR expression in association with FGFRs in TCGA database. We found that LDLR is moderately reverse associated with FGFR1 and FGFR3 in patients (data not show), which was consistent with the data we found for EOC cells.

To further test the effects of LDLR expression on cisplatin responsiveness in vivo, we performed the xenograft tumor with cisplatin treatment procedure (see 'Methods' section) in mice bearing MDAH-2774,
TOV-21G, and SKOV3 EOC cells. We found that the tumor with shLuc-infected MDAH-2774 cells could only exerted a minor degree of tumor suppression by Cisplatin treatments; however, tumors with LDLR-knockdown tumors caused by shLDLR were dramatically ameliorated by the same treatment procedure (Fig. 6A). In contrast, the tumors with pLenti-infected SKOV3 cells could be inhibited by the cisplatin treatment procedure, and the effects of treatment were comparable in tumors in which LDLR cDNA was stably expressed (Fig. 6B). To further confirm the effects of LDLR expression on cisplatin responsiveness, we performed the same procedure in tumors with shLuc-infected TOV-21G cells and found 
A

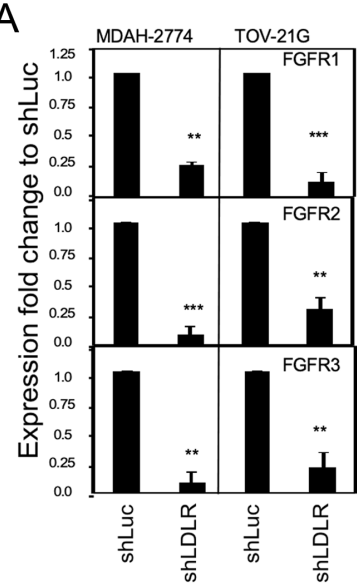

B
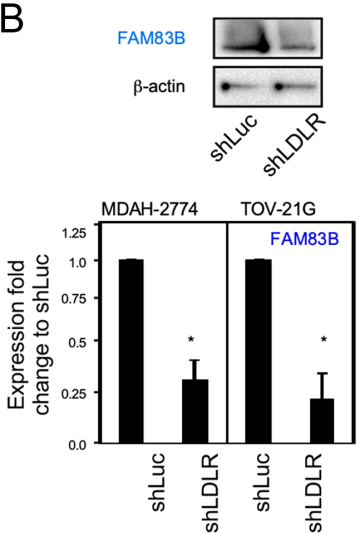

C

\begin{tabular}{|c|c|c|}
\hline gene & shLuc & ShFAM83B \\
\hline FAM83B & $100 \%$ & $14.12 \%$ \\
\hline LDLR & $100 \%$ & $98.5 \pm 4.8 \%$ \\
\hline FGFR1 & $100 \%$ & $71.16 \pm 6.5 \%$ \\
\hline FGFR2 & $100 \%$ & $50.82 \pm 5.2 \%$ \\
\hline FGFR3 & $100 \%$ & $47.45 \pm 3.9 \%$ \\
\hline
\end{tabular}

D

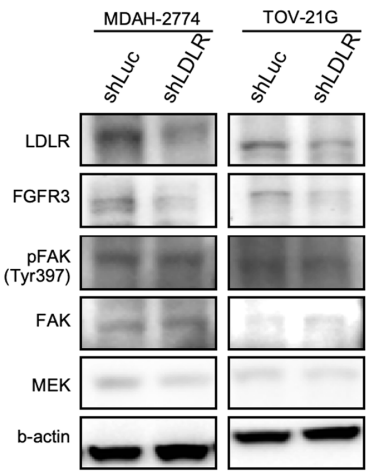

$E$

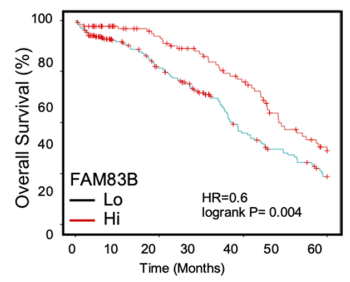

Figure 4

LDLR $\rightarrow$ FAM83B $\rightarrow$ FGFR3 regulatory axis in cisplatin insensitivity. (A) Confirmation of LDLR-knockdown effect on FGFR1 (panels on left-hand side), FGFR2 (panels in the middle), and FGFR3 (panels on right-hand side) mRNA expressions. The mRNA expressions were measured in MDAH-2774 and TOV-21G shLuc vs shLDLR cells. (B) Confirmation of LDLR-knockdown effect on protein (upper panels) and mRNA (lower panels) expression of FAM83B. The FAM83B expression were measured in MDAH-2774 or TOV-21G shLuc vs shLDLR cells. (C) Knockdown FAM83B effect on LDLR, FGFR1 3, etc. mRNA expressions. Knocking down FAM83B reduced the expressions of FGFR2 and FGFR3 and slightly decreased the expression of FGFR1, but did not alter LDLR mRNA expression. (D) The FGFR

downstream signaling, e.g., as indicated by pFAK/FAK and MEK amounts, was measured. The representative blots are shown, and beta-actin served as the loading control. (E) FAM83B was negatively correlated to EOC patient overall survival. The DriverDB.v2 platform was used to analyze TCGA data regarding the 5-year overall survival of EOC patients. Total 302 EOC patients were included, and the mean of overall expression level was used to divide hi vs lo expression of FAM83B. Log-rank $P$ value $=0.004$, where hazard ratio is 0.6 . The ** indicates a significant difference due to a p-value $<0.01$, and $* \star *$ indicates a $P$ value $<0.001$.

very little response. However, the tumors with shLDLRinfected TOV-21G cells could be almost abolished with the treatment procedure (Fig. $6 \mathrm{C}$ ).

In brief, the results of the mechanistic dissection shown in Figs 4 and 5 revealed an LDLR $\rightarrow$ LPC $\rightarrow$ FAM83B $\rightarrow$ FGFRs $\rightarrow$ platinum insensitivity axis in EOC, while the results shown in Fig. 6 supported

A

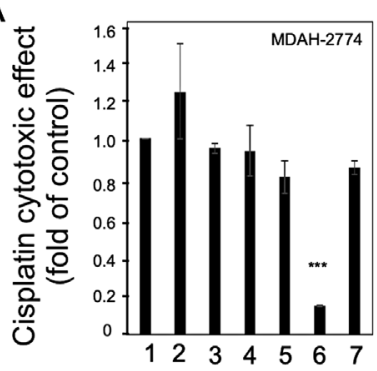

Cisplatin $(20 \mu \mathrm{M})-+\ldots+-++$

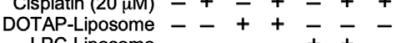

LPC-Liposome ---+++

C

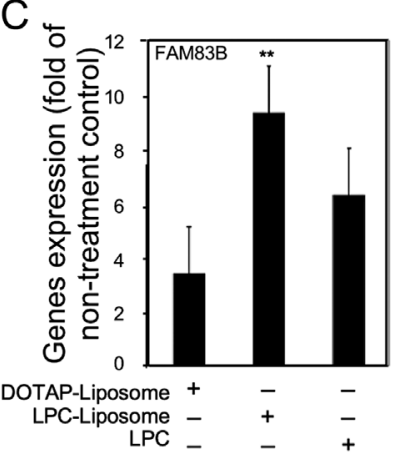

$\mathrm{B}$

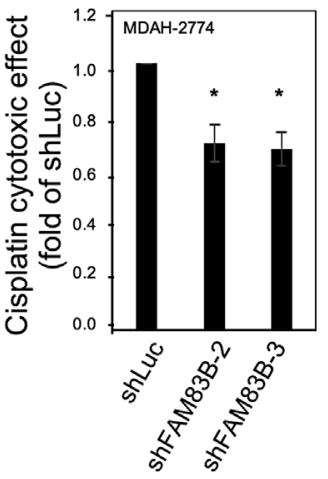

\section{Figure 5}

LDLR $\rightarrow$ FAM83B $\rightarrow$ FGFR3 regulatory axis in cisplatin insensitivity. (A) LPC-liposome boosted cisplatin cytotoxic efficacy. Various treatments, e.g., w/cisplatin vs w/o cisplatin (lane 1 vs 2), DOTAP-liposome (w/cisplatin vs w/o cisplatin $20 \mu \mathrm{M}$; lane 3 vs 4), LPC-liposome (w/cisplatin vs w/o cisplatin $20 \mu \mathrm{M}$; lanes 5 vs 6), and co-treatment with LPC and cisplatin (lane 7), were tested. (B) FAM83B knockdown enhanced the cytotoxic effect of cisplatin in MDAH-2774 cells. The cytotoxic effect of cisplatin in shLuc cells was compared with two clones of ShFAM83B (shFAM83B-2 and shFAM83B-3). (C) The LPC-liposome upregulated FAM83B mRNA expressions. (D) The LPC-liposome upregulated FGFR3 mRNA expressions. The * indicates a $P$ value less than $0.05 ;$ ** indicates a $P$ value less than 0.01 ; and $* \star *$ indicates a $P$ value less than 0.001 .

the conclusion that the expression of LDLR in EOCs determined their cisplatin responsiveness.

\section{Discussion}

In this study, we found that the differential expression of the LDL/R-route in EOCs, as revealed in histological variations, determines the platinum-based therapy insensitivity of those EOCs. The mechanism underlying this could involve the LDLR $\rightarrow$ LPC $\rightarrow$ FAM $83 B \rightarrow$ FGFRs regulatory axis. The mechanism of LDLR in platinum chemosensitivity can be explained in several steps as the illustrative scheme shown in Fig. 6D. First, the circulating LDL could affect cancer cells; second, the LDLR engulfs LDL in association with LDLRAP (LDLR Associate Protein); third, the engulfed LDL could then unload lipids by LPL. 
A
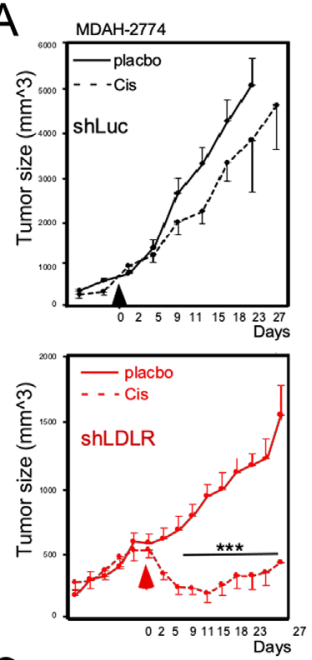

C
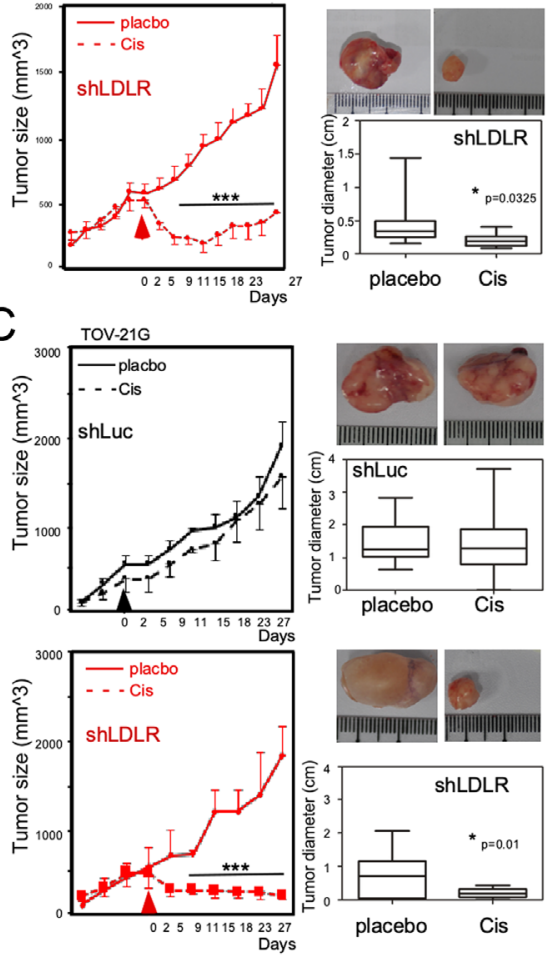

害

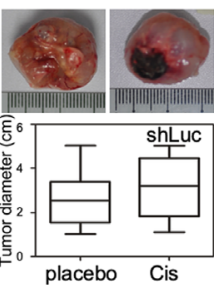

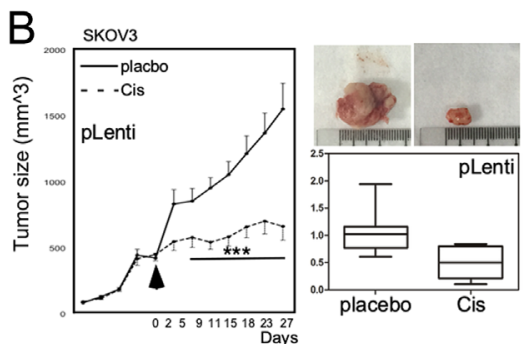

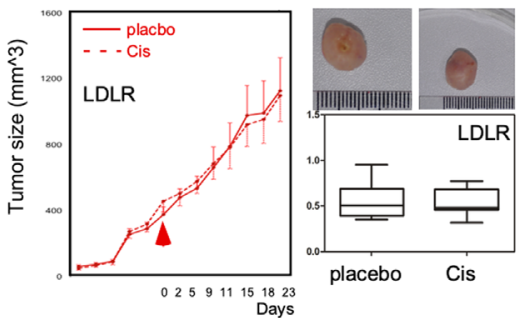

LDL/R-route mediated platinum insensitivity

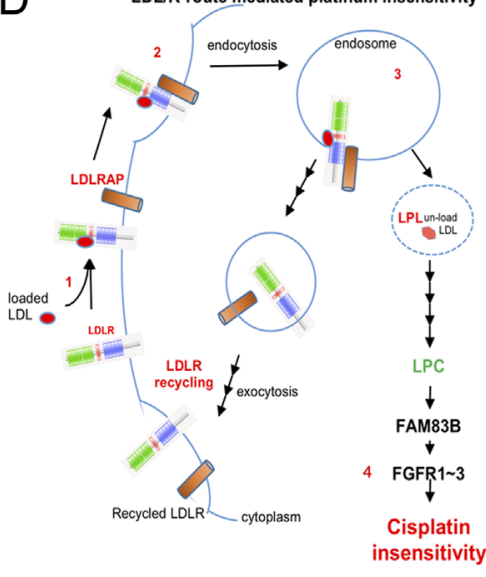

\section{Figure 6}

The expressions of LDLR determine cisplatin sensitivity in EOC xenograft tumors. Tumorsuppressive effect of cisplatin ( $6 \mathrm{mg} / \mathrm{kg} / \mathrm{mice})$ in EOC cell (A. MDAH-2774; B. SKOV3; C. TOV-21G) xenograft mouse models. The left-hand side panels of each EOC tumor model show the tumor growth curve. The mice received cisplatin treatment (I.P.; 3 times/week for 3 4 weeks) while the given tumor grew to $500 \mathrm{~mm}^{3}$. The right-hand side panels show a representative image (upper-right) and quantitation (lower-right) of the tumors. The cisplatin therapy efficacy levels of shLuc (upper panels) and shLDLR (lower panels) in mice bearing MDAH-2774 (A) and TOV-21G cells (C) were compared, as were those of pLenti(upper panels) and LDLR (lower panels) in mice bearing SKOV3 cells (B). (D) Schematic illustration of LDL/R-route-mediated lipidome reprogramming to facilitate LD lipid remodeling and FGFR signaling in platinum-based therapy sensitivity. The * indicates a significant difference due to a $P$ value $<0.05$, and $* * *$ indicates a $P$ value $<0.001$. Each experimental group contained 10 mice with 20 tumor sites.
The imported lipidome could then decreased LPC amount. Moreover, the LPC amount could trigger the FAM83B expression and the consequence FGFRs expression; fourth, alternation in LPC, FAM83B and FGFRs expressions could lead to cisplatin insensitivity. The potential impacts of our findings are discussed below:

\section{Translational value of LDLR as a biomarker for chemotherapy responsiveness}

The effects of LDL/R route and related lipidome expression on chemosensitivity have previously been hypothesized but had not previously been verified (Huang et al. 2016). With regard to platinum-based therapy, it was previously shown that the latency from initial adjuvant platinum therapy to resistance is around 90 250 days in lung adenocarcinoma (Wu et al. 2015). It has been speculated that the mechanism underlying this resistance could involve cholesterol-induced ABCG2 expression, with the
ABCG2 being recognized as a channel for pumping out lipophilic wastes, for example, platinum chemoagents. Interestingly, $\mathrm{LD}$ function is related to lipid transport through ABC proteins (Baldan et al. 2009, Gulati et al. 2015). Relatedly, a recent study using transcriptome and metabolomics analyses in NCI-60 cell lines found that lipoprotein uptake is one of the hallmark events in platinum sensitivity (Cavill et al. 2011). As for other chemoagents, other evidence has shown that cholesterol uptake (potentially via LDLR) could be an important event for developing gemcitabine resistance in cases of pancreatic cancer, which has caused such uptake to be considered an excellent therapeutic target (Guillaumond et al. 2015). In this study, we discovered an LDLR $\rightarrow$ LPC $\rightarrow$ FAM83B $\rightarrow$ FGFRs axis for platinum sensitivity. Taking advantage of this discovery, we then implemented the use of LPCliposome-encapsulated cisplatin as a new chemoagent (Fig. 5A). In terms of translating to clinical usage, further delicate technical and efficacy improvement of
(C) 2020 Society for Endocrinology Published by Bioscientifica Ltd. Printed in Great Britain 
LPC-liposome-cisplatin in multiple cancer types and in vivo delivery should be conducted.

\section{Targeting LDLR as part of future therapies for EOCs}

Proprotein convertase subtilisin/kexin type 9 (PCSK9) is a soluble member of the mammalian proprotein convertase family of secretory serine endoproteases (Seidah et al. 2003). Circulating PCSK9 is known to degrade LDLR (Lagace et al. 2006) via binding on the EGF-like repeat A site of LDLR, which causes the recycling activity to be reduced and, thus, causes the degradation of LDLR (Zhang et al. 2007). The mechanism-of-action of PCSK-9 inhibitors (such as alirocumab and evolocumab) exerts anti-degrading liver LDLR activity; therefore, these PCSK-9 inhibitors enhance LDLR recycling to reduce circulating LDL levels. In this study, we discovered that the $\mathrm{LDL} / \mathrm{R}$ route reduces platinum efficacy. Therefore, one of the strategies for targeting the LDL/R-route consists of reducing systemic LDL levels. Introducing a PCSK-9 inhibitor in the newly developed LPC-liposomecisplatin for this purpose exhibited great potential. On the other hand, an LDL/R-route-targeting strategy could also include degraded cancer LDLR. One in vitro study showed that PCSK-9 could degrade LDLR by interacting with glypican-3 in liver cancer cells (Ly et al. 2016). The development of PCSK-9 peptide for degrading LDLR (Lagace 2014) is also a hypothetical strategy for platinumbased therapy.

In conclusion, this study discovered that LDLR expression is a major determinant for platinum chemosensitivity. Furthermore, the novel $\mathrm{LDLR} \rightarrow \mathrm{LPC} \rightarrow \mathrm{FAM} 83 \mathrm{~B} \rightarrow \mathrm{FGFRs}$ regulatory axis revealed by the trans-omics analyses conducted in this investigation might explain platinum chemosensitivity discrepancies.

\section{Supplementary materials}

This is linked to the online version of the paper at https://doi.org/10.1530/ ERC-19-0095.

\section{Declaration of interest}

The authors declare that there is no conflict of interest that could be perceived as prejudicing the impartiality of the research reported.

\section{Funding}

This work was supported by the Taiwan Ministry of Science and Technology (grant numbers MOST108-2314-B-039-043-MY3, MOST1082320-B-039-017-, $\quad$ MOST108-2314-B-039-042-MY3, MOST107-2320-B039-017-MY3, and MOST106-2221-E-039-011-MY3); the National Health

C) 2020 Society for Endocrinology Published by Bioscientifica Ltd. Printed in Great Britain
Research Institute (grant number NHRI-EX107-10705BI); and China Medical University/Hospital (grant numbers CMU107-S-05, CMU107-TC-02, CMU108-MF-33，DMR-108-079，DMR-108-080，DMR-CELL-17014，DMRCELL-1806).

\section{Author contribution statement}

W C Chang collected the clinical samples, conceptualized the study, and drafted the manuscript. H C Wang performed the animal experiment and drafted the methodology section, while W C Cheng performed the bioinformatics analysis. J C Yang performed HPLC for the platinum measurements and assisted with the in vitro experiment. W M Chung and Y P Ho helped with the immunohistochemistry study. Y C Hung supported the study, analyzed the data, and edited the manuscript. W L Ma conceptualized the study, coordinated the research project, supported the project, and edited/approved the final version of the manuscript.

\section{Acknowledgements}

The authors appreciate the guidance provided by Dr Keen Chung regarding the liposome preparation for drug delivery. They also appreciate the technical support provided by Lipotype $\mathrm{GmbH}$ (Dresden, Germany) and Taiwan-BioActive Lipid Ltd. Co. (Taiwan) regarding the lipidome profiling and bioinformatics analysis. They also wish to thank Prof. Chawnshang Chang of the University of Rochester and Prof. Chiung-Kwei Huang of Brown University for their generosity in providing and verifying the RCC and cholangicarcinoma cell lines. Availability of data and materials: all datasets are available from the corresponding author upon reasonable request.

\section{References}

Baldan A, Bojanic DD \& Edwards PA 2009 The ABCs of sterol transport. Journal of Lipid Research $\mathbf{5 0}$ (Supplement) S80-S85. (https://doi. org/10.1194/jlr.R800044-JLR200)

Bellmunt J, Pons F \& Orsola A 2013 Molecular determinants of response to cisplatin-based neoadjuvant chemotherapy. Current Opinion in Urology 23 466-471. (https://doi.org/10.1097/ MOU.0b013e328363de67)

Berghmans T, Scherpereel A, Meert AP, Giner V, Lecomte J, Lafitte JJ, Leclercq N, Paesmans M, Sculier JP \& European Lung Cancer Working Party (ELCWP) 2017 A Phase III randomized study comparing a chemotherapy with cisplatin and etoposide to a etoposide regimen without cisplatin for patients with extensive small-cell lung cancer. Frontiers in Oncology 7 217. (https://doi. org/10.3389/fonc.2017.00217)

Cavill R, Kamburov A, Ellis JK, Athersuch TJ, Blagrove MS, Herwig R, Ebbels TM \& Keun HC 2011 Consensus-phenotype integration of transcriptomic and metabolomic data implies a role for metabolism in the chemosensitivity of tumour cells. PLoS Computational Biology 7 e1001113. (https://doi.org/10.1371/journal.pcbi.1001113)

Chang WC, Huang SF, Lee YM, Lai HC, Cheng BH, Cheng WC, Ho JY, Jeng LB \& Ma WL 2016 Cholesterol import and steroidogenesis are biosignatures for gastric cancer patient survival. Oncotarget 8 692-704. (https://doi.org/10.18632/oncotarget.13524)

Chang WC, Huang SF, Lee YM, Lai HC, Cheng BH, Cheng WC, Ho JY, Jeng LB \& Ma WL 2017 Cholesterol import and steroidogenesis are biosignatures for gastric cancer patient survival. Oncotarget $\mathbf{8}$ 692-704. (https://doi.org/10.18632/oncotarget.13524)

Chen L, Chang WC, Hung YC, Chang YY, Bao BY, Huang HC, Chung WM, Shyr CR \& Ma WL 2014 Androgen receptor increases CD133 expression and progenitor-like population that associate with 
cisplatin resistance in endometrial cancer cell line. Reproductive Sciences 21 386-394. (https://doi.org/10.1177/1933719113497281)

Chen L, Bao BY, Chang WC, Ho JY, Cheng BH, Wang CL, Tang Q, Cheng WC, Chang HW, Hung YC, et al. 2018 Short androgen receptor poly-glutamine-promoted endometrial cancer is associated with benzo[a]pyrene-mediated aryl hydrocarbon receptor activation. Journal of Cellular and Molecular Medicine 22 46-56. (https://doi. org $/ 10.1111 /$ jcmm.13291)

Cheng WC, Chung IF, Chen CY, Sun HJ, Fen JJ, Tang WC, Chang TY, Wong TT \& Wang HW 2014 DriverDB: an exome sequencing database for cancer driver gene identification. Nucleic Acids Research 42 D1048-D1054. (https://doi.org/10.1093/nar/gkt1025)

Chiang YC, Wang RY, Huang CL, Chen SH, Ho WJ, Lane HY, Ho IK, Yang HT \& Ma WL 2017 Reduced dosing and liability in methadone maintenance treatment by targeting oestrogen signal for morphine addiction. Journal of Cellular and Molecular Medicine 21 3552-3564. (https://doi.org/10.1111/jcmm.13266)

Chou TC 2010 Drug combination studies and their synergy quantification using the Chou-Talalay method. Cancer Research 70 440-446. (https://doi.org/10.1158/0008-5472.CAN-09-1947)

Chou TC \& Talalay P 1984 Quantitative analysis of dose-effect relationships: the combined effects of multiple drugs or enzyme inhibitors. Advances in Enzyme Regulation 22 27-55. (https://doi. org/10.1016/0065-2571(84)90007-4)

Chung IF, Chen CY, Su SC, Li CY, Wu KJ, Wang HW \& Cheng WC 2016 DriverDBv2: a database for human cancer driver gene research. Nucleic Acids Research 44 D975-D979. (https://doi.org/10.1093/nar/ gkv1314)

Croft D, O'Kelly G, Wu G, Haw R, Gillespie M, Matthews L, Caudy M, Garapati P, Gopinath G, Jassal B, et al. 2011 Reactome: a database of reactions, pathways and biological processes. Nucleic Acids Research 39 D691-D697. (https://doi.org/10.1093/nar/gkq1018)

Dahm-Kahler P, Borgfeldt C, Holmberg E, Staf C, Falconer H, Bjurberg M, Kjolhede P, Rosenberg P, Stalberg K, Hogberg T, et al. 2017 Population-based study of survival for women with serous cancer of the ovary, fallopian tube, peritoneum or undesignated origin - on behalf of the Swedish gynecological cancer group (SweGCG). Gynecologic Oncology 144 167-173. (https://doi. org/10.1016/j.ygyno.2016.10.039)

de Castria TB, da Silva EM, Gois AF \& Riera R 2013 Cisplatin versus carboplatin in combination with third-generation drugs for advanced non-small cell lung cancer. Cochrane Database of Systematic Reviews 8 CD009256. (https://doi.org/10.1002/14651858.CD009256.pub2)

Ejsing CS, Sampaio JL, Surendranath V, Duchoslav E, Ekroos K, Klemm RW, Simons K \& Shevchenko A 2009 Global analysis of the yeast lipidome by quantitative shotgun mass spectrometry. PNAS 106 2136-2141. (https://doi.org/10.1073/pnas.0811700106)

Falcetta FS, Medeiros LR, Edelweiss MI, Pohlmann PR, Stein AT \& Rosa DD 2016 Adjuvant platinum-based chemotherapy for early stage cervical cancer. Cochrane Database of Systematic Reviews $\mathbf{1 1}$ CD005342. (https://doi.org/10.1002/14651858.CD005342.pub4)

Ferreira JA, Peixoto A, Neves M, Gaiteiro C, Reis CA, Assaraf YG \& Santos LL 2016 Mechanisms of cisplatin resistance and targeting of cancer stem cells: adding glycosylation to the equation. Drug Resistance Updates 24 34-54. (https://doi.org/10.1016/j. drup.2015.11.003)

Galdy S, Cella CA, Spada F, Murgioni S, Frezza AM, Ravenda SP, Zampino MG \& Fazio N 2016 Systemic therapy beyond first-line in advanced gastric cancer: an overview of the main randomized clinical trials. Critical Reviews in Oncology/Hematology 99 1-12. (https://doi.org/10.1016/j.critrevonc.2015.09.004)

Glasspool RM \& McNeish IA 2013 Clear cell carcinoma of ovary and uterus. Current Oncology Reports 15 566-572. (https://doi. org/10.1007/s11912-013-0346-0)

Guillaumond F, Bidaut G, Ouaissi M, Servais S, Gouirand V, Olivares O, Lac S, Borge L, Roques J, Gayet O, et al. 2015 Cholesterol uptake disruption, in association with chemotherapy, is a promising combined metabolic therapy for pancreatic adenocarcinoma. PNAS 112 2473-2478. (https://doi.org/10.1073/pnas.1421601112)

Gulati S, Balderes D, Kim C, Guo ZA, Wilcox L, Area-Gomez E, Snider J, Wolinski H, Stagljar I, Granato JT, et al. 2015 ATP-binding cassette transporters and sterol O-acyltransferases interact at membrane microdomains to modulate sterol uptake and esterification. FASEB Journal 29 4682-4694. (https://doi.org/10.1096/fj.14-264796)

Hammond ME, Hayes DF, Dowsett M, Allred DC, Hagerty KL, Badve S, Fitzgibbons PL, Francis G, Goldstein NS, Hayes M, et al. 2010 American Society of Clinical Oncology/College of American Pathologists guideline recommendations for immunohistochemical testing of estrogen and progesterone receptors in breast cancer. Journal of Clinical Oncology 28 2784-2795. (https://doi.org/10.1200/ JCO.2009.25.6529)

Huang J, Li L, Lian J, Schauer S, Vesely PW, Kratky D, Hoefler G \& Lehner R 2016 Tumor-induced hyperlipidemia contributes to tumor growth. Cell Reports 15 336-348. (https://doi.org/10.1016/j. celrep.2016.03.020)

Hung YC, Chang WC, Chen LM, Chang YY, Wu LY, Chung WM, Lin TY, Chen LC \& Ma WL 2014 Non-genomic estrogen/estrogen receptor alpha promotes cellular malignancy of immature ovarian teratoma in vitro. Journal of Cellular Physiology 229 752-761. (https://doi. $\operatorname{org} / 10.1002 /$ jcp.24495)

Ishikawa T, Abe S, Watanabe T, Nozawa Y, Sano T, Iwanaga A, Seki K, Honma T \& Yoshida T 2016 Improved survival with double platinum therapy transcatheter arterial infusion using cisplatin and transcatheter arterial chemoembolization using miriplatin for BCLC-B hepatocellular carcinoma. Molecular and Clinical Oncology 5 511-516. (https://doi.org/10.3892/mco.2016.998)

Jang SC, Kim OY, Yoon CM, Choi DS, Roh TY, Park J, Nilsson J, Lotvall J, Kim YK \& Gho YS 2013 Bioinspired exosome-mimetic nanovesicles for targeted delivery of chemotherapeutics to malignant tumors. ACS Nano 7 7698-7710. (https://doi.org/10.1021/ $\mathrm{nn} 402232 \mathrm{~g}$ )

Johnson N, Bryant A, Miles T, Hogberg T \& Cornes P 2011 Adjuvant chemotherapy for endometrial cancer after hysterectomy. Cochrane Database of Systematic Reviews 10 CD003175. (https://doi. org/10.1002/14651858.CD003175.pub2)

Kanehisa M, Goto S, Sato Y, Furumichi M \& Tanabe M 2012 KEGG for integration and interpretation of large-scale molecular data sets. Nucleic Acids Research 40 D109-D114. (https://doi.org/10.1093/nar/ gkr988)

Kim D, Pertea G, Trapnell C, Pimentel H, Kelley R \& Salzberg SL 2013 TopHat2: accurate alignment of transcriptomes in the presence of insertions, deletions and gene fusions. Genome Biology 14 R36. (https://doi.org/10.1186/gb-2013-14-4-r36)

Klose C, Surma MA \& Simons K 2013 Organellar lipidomics background and perspectives. Current Opinion in Cell Biology 25 406-413. (https://doi.org/10.1016/j.ceb.2013.03.005)

Klotz DM \& Wimberger P 2017 Cells of origin of ovarian cancer: ovarian surface epithelium or Fallopian tube? Archives of Gynecology and Obstetrics 296 1055-1062. (https://doi.org/10.1007/s00404-017$4529-\mathrm{z})$

Lagace TA 2014 PCSK9 and LDLR degradation: regulatory mechanisms in circulation and in cells. Current Opinion in Lipidology 25 387-393. (https://doi.org/10.1097/MOL.0000000000000114)

Lagace TA, Curtis DE, Garuti R, McNutt MC, Park SW, Prather HB, Anderson NN, Ho YK, Hammer RE \& Horton JD 2006 Secreted PCSK9 decreases the number of LDL receptors in hepatocytes and in livers of parabiotic mice. Journal of Clinical Investigation $\mathbf{1 1 6}$ 2995-3005. (https://doi.org/10.1172/JCI29383)

Lai HC, Yeh CC, Jeng LB, Huang SF, Liao PY, Lei FJ, Cheng WC, Hsu CL, Cai X, Chang C, et al. 2016 Androgen receptor mitigates postoperative disease progression of hepatocellular carcinoma by suppressing CD90+ populations and cell migration and by https://erc.bioscientifica.com

https://doi.org/10.1530/ERC-19-0095 (c) 2020 Society for Endocrinology Published by Bioscientifica Ltd. Printed in Great Britain 
promoting anoikis in circulating tumor cells. Oncotarget 7 46448-46465. (https://doi.org/10.18632/oncotarget.10186)

Lawrie TA, Winter-Roach BA, Heus P \& Kitchener HC 2015 Adjuvant (post-surgery) chemotherapy for early stage epithelial ovarian cancer. Cochrane Database of Systematic Reviews 12 CD004706. (https://doi. org/10.1002/14651858.CD004706.pub5)

Ledermann JA, Luvero D, Shafer A, O'Connor D, Mangili G, Friedlander M, Pfisterer J, Mirza MR, Kim JW, Alexandre J, et al. 2014 Gynecologic Cancer InterGroup (GCIG) consensus review for mucinous ovarian carcinoma. International Journal of Gynecological Cancer 24 S14-S19. (https://doi.org/10.1097/IGC.0000000000000296)

Lee YY, Kim TJ, Kim MJ, Kim HJ, Song T, Kim MK, Choi CH, Lee JW, Bae DS \& Kim BG 2011 Prognosis of ovarian clear cell carcinoma compared to other histological subtypes: a meta-analysis. Gynecologic Oncology 122 541-547. (https://doi.org/10.1016/j.ygyno.2011.05.009)

Lee YM, Chang WC \& Ma WL 2016 Hypothesis: solid tumours behave as systemic metabolic dictators. Journal of Cellular and Molecular Medicine 20 1076-1085. (https://doi.org/10.1111/jcmm.12794)

Levental KR, Surma MA, Skinkle AD, Lorent JH, Zhou Y, Klose C, Chang JT, Hancock JF \& Levental I 2017 omega-3 polyunsaturated fatty acids direct differentiation of the membrane phenotype in mesenchymal stem cells to potentiate osteogenesis. Science Advances 3 eaao1193. (https://doi.org/10.1126/sciadv.aao1193)

Liebisch G, Binder M, Schifferer R, Langmann T, Schulz B \& Schmitz G 2006 High throughput quantification of cholesterol and cholesteryl ester by electrospray ionization tandem mass spectrometry (ESI-MS/ MS). Biochimica and Biophysica Acta 1761 121-128. (https://doi. org/10.1016/j.bbalip.2005.12.007)

Ly K, Essalmani R, Desjardins R, Seidah NG \& Day R 2016 An unbiased mass spectrometry approach identifies Glypican-3 as an interactor of proprotein convertase subtilisin/Kexin Type 9 (PCSK9) and low density lipoprotein receptor (LDLR) in hepatocellular carcinoma cells. Journal of Biological Chemistry 291 24676-24687. (https://doi. org/10.1074/jbc.M116.746883)

Ma WL, Hsu CL, Wu MH, Wu CT, Wu CC, Lai JJ, Jou YS, Chen CW, Yeh S \& Chang C 2008 Androgen receptor is a new potential therapeutic target for the treatment of hepatocellular carcinoma. Gastroenterology 135 947-955, 955.e941-955.e945. (https://doi. org/10.1053/j.gastro.2008.05.046)

Ma WL, Hsu CL, Yeh CC, Wu MH, Huang CK, Jeng LB, Hung YC, Lin TY, Yeh S \& Chang C 2012 Hepatic androgen receptor suppresses hepatocellular carcinoma metastasis through modulation of cell migration and anoikis. Hepatology 56 176-185. (https://doi. org/10.1002/hep.25644)

Ma WL, Jeng LB, Lai HC, Liao PY \& Chang C 2014 Androgen receptor enhances cell adhesion and decreases cell migration via modulating beta1-integrin-AKT signaling in hepatocellular carcinoma cells. Cancer Letters 351 64-71. (https://doi.org/10.1016/j. canlet.2014.05.017)

Malka D, Cervera P, Foulon S, Trarbach T, de la Fouchardiere C, Boucher E, Fartoux L, Faivre S, Blanc JF, Viret F, et al. 2014 Gemcitabine and oxaliplatin with or without cetuximab in advanced biliary-tract cancer (BINGO): a randomised, open-label, noncomparative phase 2 trial. Lancet: Oncology 15 819-828. (https://doi. org/10.1016/S1470-2045(14)70212-8)

Matulonis UA, Sood AK, Fallowfield L, Howitt BE, Sehouli J \& Karlan BY 2016 Ovarian cancer. Nature Reviews: Disease Primers 216061. (https://doi.org/10.1038/nrdp.2016.61)

McCluggage WG 2011 Morphological subtypes of ovarian carcinoma: a review with emphasis on new developments and pathogenesis. Pathology 43 420-432. (https://doi.org/10.1097/ PAT.0b013e328348a6e7)

Mizuno M, Kikkawa F, Shibata K, Kajiyama H, Ino K, Kawai M, Nagasaka T \& Nomura S 2006 Long-term follow-up and prognostic factor analysis in clear cell adenocarcinoma of the ovary. Journal of Surgical Oncology 94 138-143. (https://doi.org/10.1002/jso.20251)
Moessinger C, Klizaite K, Steinhagen A, Philippou-Massier J, Shevchenko A, Hoch M, Ejsing CS \& Thiele C 2014 Two different pathways of phosphatidylcholine synthesis, the Kennedy Pathway and the Lands Cycle, differentially regulate cellular triacylglycerol storage. BMC Cell Biology 15 43. (https://doi.org/10.1186/s12860014-0043-3)

Nieman KM, Kenny HA, Penicka CV, Ladanyi A, Buell-Gutbrod R, Zillhardt MR, Romero IL, Carey MS, Mills GB, Hotamisligil GS, et al. 2011 Adipocytes promote ovarian cancer metastasis and provide energy for rapid tumor growth. Nature Medicine 17 1498-1503. (https://doi.org/10.1038/nm.2492)

Nishimura S, Tsuda H, Ito K, Takano M, Terai Y, Jobo T, Kigawa J, Sugiyama T, Yaegashi N \& Aoki D 2010 Differential expression of hypoxia-inducible protein 2 among different histological types of epithelial ovarian cancer and in clear cell adenocarcinomas. International Journal of Gynecological Cancer 20 220-226. (https://doi. org/10.1111/IGC.0b013e3181ca1e16)

Nose N, Sugio K, Oyama T, Nozoe T, Uramoto H, Iwata T, Onitsuka T \& Yasumoto K 2009 Association between estrogen receptor-beta expression and epidermal growth factor receptor mutation in the postoperative prognosis of adenocarcinoma of the lung. Journal of Clinical Oncology 27 411-417. (https://doi.org/10.1200/ JCO.2008.18.3251)

Ong SG, Chitneni M, Lee KS, Ming LC \& Yuen KH 2016 Evaluation of extrusion technique for nanosizing liposomes. Pharmaceutics 8 E36. (https://doi.org/10.3390/pharmaceutics8040036)

Poonawalla IB, Parikh RC, Du XL, VonVille HM \& Lairson DR 2015 Cost effectiveness of chemotherapeutic agents and targeted biologics in ovarian cancer: a systematic review. Pharmacoeconomics $\mathbf{3 3}$ 1155-1185. (https://doi.org/10.1007/s40273-015-0304-9)

Prendergast EN, Holzapfel M, Mueller JJ, Leitao Jr MM, Gunderson CC, Moore KN, Erickson BK, Leath 3rd CA, Diaz Moore ES, Cohen JG, et al. 2017 Three versus six cycles of adjuvant platinum-based chemotherapy in early stage clear cell ovarian carcinoma - a multiinstitutional cohort. Gynecologic Oncology 144 274-278. (https://doi. org/10.1016/j.ygyno.2016.12.004)

Ricci F, Affatato R, Carrassa L \& Damia G 2018 Recent insights into mucinous ovarian carcinoma. International Journal of Molecular Sciences 19 E1569. (https://doi.org/10.3390/ijms19061569)

Roupret M, Neuzillet Y, Masson-Lecomte A, Colin P, Comperat E, Dubosq F, Houede N, Larre S, Pignot G, Puech P, et al. 2016 CCAFU French national guidelines 2016-2018 on bladder cancer. Progres en Urologie 27 (Supplement 1) S67-S91. (https://doi.org/10.1016/S11667087(16)30704-7)

Sampaio JL, Gerl MJ, Klose C, Ejsing CS, Beug H, Simons K \& Shevchenko A 2011 Membrane lipidome of an epithelial cell line. PNAS 108 1903-1907. (https://doi.org/10.1073/pnas.1019267108)

Schaefer CF, Anthony K, Krupa S, Buchoff J, Day M, Hannay T \& Buetow KH 2009 PID: the pathway interaction database. Nucleic Acids Research 37 D674-D679. (https://doi.org/10.1093/nar/ gkn653)

Seidah NG, Benjannet S, Wickham L, Marcinkiewicz J, Jasmin SB, Stifani S, Basak A, Prat A \& Chretien M 2003 The secretory proprotein convertase neural apoptosis-regulated convertase 1 (NARC-1): liver regeneration and neuronal differentiation. PNAS 100 928-933. (https://doi.org/10.1073/pnas.0335507100)

Shevchuk MM, Winkler-Monsanto B, Fenoglio CM \& Richart RM 1981 Clear cell carcinoma of the ovary: a clinicopathologic study with review of the literature. Cancer 47 1344-1351. (https://doi. org/10.1002/1097-0142(19810315)47:6<1344::aidcncr2820470618>3.0.co;2-3)

Subramanian A, Tamayo P, Mootha VK, Mukherjee S, Ebert BL, Gillette MA, Paulovich A, Pomeroy SL, Golub TR, Lander ES, et al. 2005 Gene set enrichment analysis: a knowledge-based approach for interpreting genome-wide expression profiles. PNAS 102 15545-15550. (https://doi.org/10.1073/pnas.0506580102) https://erc bioscientifica.com

https://doi.org/10.1530/ERC-19-0095
C) 2020 Society for Endocrinology Published by Bioscientifica Ltd. Printed in Great Britain 
Sugiyama T, Kamura T, Kigawa J, Terakawa N, Kikuchi Y, Kita T, Suzuki M, Sato I \& Taguchi K 2000 Clinical characteristics of clear cell carcinoma of the ovary: a distinct histologic type with poor prognosis and resistance to platinum-based chemotherapy. Cancer $\mathbf{8 8}$ 2584-2589. (https://doi.org/10.1002/1097-

0142(20000601)88:11<2584::AID-CNCR22>3.0.CO;2-5)

Surma MA, Herzog R, Vasilj A, Klose C, Christinat N, Morin-Rivron D, Simons K, Masoodi M \& Sampaio JL 2015 An automated shotgun lipidomics platform for high throughput, comprehensive, and quantitative analysis of blood plasma intact lipids. European Journal of Lipid Science and Technology 117 1540-1549. (https://doi. org/10.1002/ejlt.201500145)

Trapnell C, Roberts A, Goff L, Pertea G, Kim D, Kelley DR, Pimentel H, Salzberg SL, Rinn JL \& Pachter L 2012 Differential gene and transcript expression analysis of RNA-seq experiments with TopHat and Cufflinks. Nature Protocols 7 562-578. (https://doi.org/10.1038/ nprot.2012.016)

Ulbright TM \& Roth LM 1985 Metastatic and independent cancers of the endometrium and ovary: a clinicopathologic study of 34 cases. Human Pathology 16 28-34. (https://doi.org/10.1016/s0046$8177(85) 80210-0)$

Vargas AN 2014 Natural history of ovarian cancer. Ecancermedicalscience 8 465. (https://doi.org/10.3332/ecancer.2014.465)
Wagner BJ, Buck JL, Seidman JD \& McCabe KM 1994 From the archives of the AFIP. Ovarian epithelial neoplasms: radiologic-pathologic correlation. RadioGraphics 14 1351-1374; quiz 1375-1356. (https:// doi.org/10.1148/radiographics.14.6.7855346)

Wang B, Rong X, Palladino END, Wang J, Fogelman AM, Martin MG, Alrefai WA, Ford DA \& Tontonoz P 2018 Phospholipid remodeling and cholesterol availability regulate intestinal stemness and tumorigenesis. Cell Stem Cell 22 206.e4-220.e4. (https://doi. org/10.1016/j.stem.2017.12.017)

Ward PS \& Thompson CB 2012 Signaling in control of cell growth and metabolism. Cold Spring Harbor Perspectives in Biology 4 a006783. (https://doi.org/10.1101/cshperspect.a006783)

Wu Y, Si R, Tang H, He Z, Zhu H, Wang L, Fan Y, Xia S, He Z \& Wang Q 2015 Cholesterol reduces the sensitivity to platinum-based chemotherapy via upregulating ABCG2 in lung adenocarcinoma. Biochemical and Biophysical Research Communications 457 614-620. (https://doi.org/10.1016/j.bbrc.2015.01.035)

Zhang DW, Lagace TA, Garuti R, Zhao Z, McDonald M, Horton JD, Cohen JC \& Hobbs HH 2007 Binding of proprotein convertase subtilisin/kexin type 9 to epidermal growth factor-like repeat A of low density lipoprotein receptor decreases receptor recycling and increases degradation. Journal of Biological Chemistry 282 18602-18612. (https://doi.org/10.1074/jbc.M702027200)

Received in final form 25 November 2019

Accepted 3 December 2019

Accepted Manuscript published online 9 December 2019 (c) 2020 Society for Endocrinology Published by Bioscientifica Ltd. Printed in Great Britain 